\title{
AVALIAÇÃO DA VARIABILIDADE GENÉTICA DE LINHAGENS DE TILÁPIA DO NILO (Oreochromis niloticus) COM O USO DO MARCADOR DE RAPD
}

\author{
Evaluation of the Genetic Variability of Ancestries of \\ Tilapia of the Nile (Oreochromis niloticus) With the Use \\ of the RAPD Marker
}

\author{
Vanessa Petronilo Vieira ${ }^{1}$ \\ Ricardo Pereria Ribeiro ${ }^{2}$ \\ Lauro Vargas ${ }^{3}$ \\ Héden Luiz Marques Moreira ${ }^{4}$ \\ Jayme Aparecido Povh ${ }^{5}$ \\ Nelson Maurício Lopera Barrero ${ }^{6}$
}

\section{Resumo}

O objetivo deste trabalho foi avaliar a variabilidade genética dentro de três linhagens de tilápia do Nilo (Oreochromis niloticus) examinadas com marcador molecular (RAPD). Foram estudadas as linhagens Chitralada (UEM/CODAPAR), Supreme proveniente da Piscicultura Aquabel, linhagens Bouaké (UEM/ CODAPAR) e Chitralada (Aquabel). Foram analisados seis primers de RAPD, os quais amplificaram no total 34 locos. A similaridade genética foi obtida pelo coeficiente de Jaccard, por meio do programa Mantel_Struct. As porcentagens de loci polimórfico foram de $64,71 \%$ para a linhagem Chitralada Codapar, 47,06\% para linhagem Su preme, 73,53\% para linhagem Boaukèe 79,41\% para Chitralada Aquabel A variabilidade genética foi determinada pelo índice de Shannon que foi 0,3090, 0,1767, 0,3272 e 0,4240, seguindo a mesma ordem acima e o índice geral de 0,3980

Palavras-chave: Oreochromis; RAPD; Variabilidade genética; Polimorfismo.

\section{Abstract}

The objective of this research was to evaluate the genetic variability of three Nile Tilapia's strains (Oreochromis niloticus) examined with molecular marker (RAPD). The strains studies were on Chitralada and Supreme proceeded from the Aquabel fish culture, and on Bouaké and Chitralada strains proceeded from the station of the Universidade Estadual de Maringa fish culture - UEM/CODAPAR. The six first primers of the RAPD were analyzed and amplified in the total of 34 locos. The genetic similarity was obtained through the Jaccard coefficient through the Mantel-Struct Program. The loci polimorfic percentage was $64.71 \%$ for the Chitralada Codapar strain, $47.06 \%$ for the Supreme strain, $73.53 \%$ for the Boauké strain, and $79.41 \%$ for the Chitralada Aquabel strain. The genetic variability determined by the Shannon index was 0.3090; 0.1767; 0.3272, and 0.4240 following the same order above and 0.3980 of the general index.

Keywords: Oreochromis niloticus; RAPD; Genetic variability.

\footnotetext{
${ }^{1}$ Zootecnista, Mestre em Zootecnia.

2 Zootecnista, Professor Adjunto do Departamento de Zootecnia da Universidade Estadual de Maringá (rpribeiro@uem.br).

${ }^{3}$ Médico Veterinário, Professor Associado do Departamento de Zootecnia da Universidade Estadual de Maringá (lvargas@uem.br).

${ }^{4}$ Engenheiro Agrônomo - Professor Adjunto do Departamento de Biologia Molecular da Universidade Federal de Pelotas.

${ }^{5}$ Zootecnista, Doutorando em Zootecnia na Universidade Estadual de Maringá.

${ }^{6}$ Médico Veterinário/Zootecnista, Doutorando em Zootecnia da Universidade Estadual de Maringá.
} 


\section{Introdução}

As tilápias pertencem à família Cichlidae e compreendem diversas espécies, todas de origem africana (PILLAY, 1990).

Existem pelo menos 77 espécies descritas no gênero Tilápia (THYS, 1969), sendo que Jhnigran; Gopalahrisshnan (1974) listaram 22 espécies que foram utilizadas em experimentos ou na produção de peixe em escala comercial.

Segundo Popma; Lovshin (1995), as tilápias de importância comercial estão divididas em três principais grupos taxonômicos, distintos basicamente pelo comportamento reprodutivo: as do gênero Tilapia spp. (incubam seus ovos em substratos), Oreochromis spp. (incubam os ovos na boca da fêmea) e Sarotherodon spp. (incubam os ovos na boca do macho ou de ambos).

Embora os marcadores morfológicos e citológicos tenham extrema importância na elucidação de uma série de eventos genéticos, esses ocorrem em um número reduzido, limitando a sua aplicação em análises genéticas. Esta limitação vem sendo resolvida a partir do desenvolvimento de uma nova classe de marcadores, ditos marcadores moleculares, que incluem os protéicos e os de DNA (FUNGARO; VIEIRA, 2001).

No início dos anos 70, várias técnicas de hibridização foram implementadas. Os avanços nos estudos da química orgânica possibilitaram a síntese de oligonucleotídeos e paralelamente observou-se o desenvolvimento de metodologias de seqüenciamento rápido de DNA, o que possibilitou determinar a seqüência de vários genes de diferentes organismos. Em poucos anos, o seqüenciamento e a síntese de oligonucleotídeos começaram a ser realizados rotineiramente nos laboratórios de pesquisa. Isso acelerou os estudos de genomas de vários organismos, pois facilitou a clonagem e o seqüenciamento de DNA (MARQUES et al., 2002).

Mullis (1983) desenvolveu a reação em cadeia da polimerase (Polymerase Chain Reaction - PCR), a qual permite amplificar in vitro o DNA. Técnicas alternativas de amplificação de ácidos nucléicos foram então desenvolvidas por diferentes centros de pesquisa.

Em 1990, ocorreu um grande avanço nos marcadores moleculares baseados na PCR, com a idéia de utilizar primers mais curtos e de seqüência arbitrária, eliminando-se a necessidade do co- nhecimento prévio da seqüência do DNA que se está estudando (FERREIRA; GRATTAPAGLA, 1998). Williams et al. (1990) patentearam essa idéia com o nome de RAPD - Random Amplified Polymorphic DNA. RAPD envolve o uso de um simples primer "arbitrário" em uma reação de PCR e como resultado da amplificação produz diversos fragmentos DNA (JONES et al., 1997). Portanto, cada fragmento é gerado a partir de uma região cromossomal que contenha dois segmentos curtos em orientação invertida e que são complementares aos primers. A seqüência de DNA é amplificada a partir de primers com 10 bases de extensão, cuja seqüência de nucleotídeo é arbitrária, não requerendo, portanto, conhecimento prévio da seqüência do DNA alvo.

O marcador de RAPD é o de menor custo, número de etapas e tempo para obter os resultados, além disso, fácil de implementar (MILACH, 1998). Por esses motivos, os marcadores moleculares do tipo RAPD estão entre os mais utilizados e difundidos.

O desenvolvimento de técnicas empregadas atualmente, na biologia molecular, permite aos geneticistas e melhoradores estudar as variações em nível de DNA, em peixes de todo o genótipo (MOREIRA, 2001).

Tipicamente, o primer arbitrário utilizado dirige a síntese de vários segmentos de DNA simultaneamente em diversos pontos do genoma, resultando assim em várias bandas no gel. O polimorfismo obtido pelo marcador RAPD é detectado pelo segmento de DNA, que são amplificados em uns indivíduos e não em outros, ou seja, este marcador possui natureza binária, isto é, o segmento amplificado está presente ou ausente (FERREIRA; GRATTAPAGLA, 1998).

Até recentemente, os ganhos genéticos foram obtidos pela seleção de fenótipos superiores e a correspondente inferência de que também eram genótipos superiores, e com isso os ganhos genéticos foram retardados devido às inconsistências do fenótipo. Hoje, há diferentes técnicas que permitem identificar diretamente o polimorfismo de DNA, marcar seqüências ou partes específicas dele e associar a genes de grande efeito (caracteres qualitativos). Com marcadores moleculares é possível ter para cada gene de grande efeito um ou mais marcadores que podem ser utilizados para identificação do fenótipo desejado (FEDERIZI, 1998). 
Devido ao fato do fenótipo ser a expressão do genótipo sob condições ambientais específicas, este pode mudar com o ambiente. Contudo, o genótipo permanece o mesmo no decorrer de seu ciclo de vida. Selecionar o fenótipo é como perseguir um alvo móvel, que muda com o ambiente. A seleção com base no genótipo do indivíduo pode evitar esse problema. Os marcadores moleculares oferecem ao melhorista a possibilidade de acessar o genótipo do indivíduo em vez de apenas o fenótipo (MILACH, 1998).

A seleção de indivíduos que apresentam o genótipo desejado em uma população segregante é uma tarefa que representa grandes desafios para o melhorista. O efeito do ambiente e a interação genótipo $\mathrm{x}$ ambiente modificam a manifestação do potencial genético de um indivíduo, causando confusão na identificação de indivíduos superiores (BARBOSA NETO, 1998).

A estimação da variação genética em peixes é muito valiosa na aqüicultura e para o manejo de reprodutores, pois possibilita a identificação de estoques em populações de seleção e para a estimação de contribuições para mistura de estoques (DINESH et al., 1996).

Segundo Koh et al. (1999), o manejo adequado e programas de seleção deveriam ser implementados para preservar a variabilidade genética e prevenir a depressão endogâmica que provavelmente resulta do estado atual de criação não planejada em peixes do gênero Symphysodon. Semelhante recomendação deveria ser feita para as larviculturas de tilápia no Brasil.

Com base no exposto, este trabalho teve como objetivo utilizar o marcador de RAPD para analisar a variabilidade genética de quatro grupos genéticos de tilápia do Nilo (Oreochromis niloticus).

\section{Material e métodos}

\section{Animais}

Os exemplares utilizados nas análises de marcadores de RAPD foram o DNA de oito exemplares da linhagem Supreme e oito da linhagem Chitralada provenientes da Empresa de Piscicultura Aquabel, localizada no município de Rolândia, no Paraná, oito exemplares da linhagem Bouaké e oito da linhagem Chitralada provenientes da Estação de Piscicultura UEM/CODAPAR, localiza- da no Distrito de Floriano no município de Maringá, Paraná.

\section{Extração de DNA}

Para a extração de DNA genômico foi utilizada a metodologia proposta por Bardakci; Skibinski (1994), com algumas modificações. Fragmentos de nadadeira caudal de aproximadamente $0,5 \mathrm{~cm}^{2}$, preservados em microtubo com etanol $70,0 \% \mathrm{em}$ freezer, foram colocados em $550,0 \mathrm{ml}$ de tampão de lise (50 mM de Tris- $\mathrm{HCl}, 50 \mathrm{mM}$ de EDTA, $100 \mathrm{mM}$ de $\mathrm{NaCl}$ e $1 \%$ de SDS) e $7 \mathrm{ml}$ de proteinase $\mathrm{K}(20 \mathrm{mg} / \mathrm{ml})$ por 12 horas em banhomaria a $45^{\circ} \mathrm{C}$. Em seguida, o DNA foi purificado com duas extrações com fenol-Tris pH 8,0 e três de clorofórmio. O DNA obtido foi precipitado com duas vezes e meia de etanol absoluto e um décimo de acetato de sódio ao volume recuperado, e ressuspendido em $60 \mathrm{ml}$ de tampão TE (10 mM de Tris $\mathrm{pH}$ 8,0 e $1 \mathrm{mM}$ de EDTA), permanecendo incubado por uma hora sob refrigeração, e posteriormente adicionado $5 \mathrm{ml}$ de RNAse $(10 \mathrm{ng} / \mathrm{ml})$.

A integridade do DNA extraído foi verificada em gel de agarose $0,7 \%$ corado com brometo de etídio e visualizada em ultravioleta (UV). A eletroforese foi conduzida em 100 volts por $45 \mathrm{minu}$ tos em um aparato $20 \times 20 \mathrm{~cm}$ (Scie Plas), usando tampão TBE 1X (500 mM de Tris- $\mathrm{HCl}, 60 \mathrm{mM}$ de ácido bórico e $83 \mathrm{mM}$ de EDTA). A imagem foi capturada por um sistema da EDAS (Kodak 1D Image Analysis 3.5).

A quantificação e confirmação da pureza do DNA (sem excesso de proteínas) foram realizadas em espectrofotômetro (Shimadzu), utilizando os comprimentos de onda de 260, para leitura do DNA.

\section{Amplificação de RAPD}

As condições de amplificações foram baseadas em Williams et al. (1990), com algumas modificações. O DNA genômico foi amplificado em um volume de reação de $25 \mu \mathrm{L}$, utilizando tampão Tris-KCl 1X (Tris-HCl 20 mM pH 8,4 e KCl 50 $\mathrm{mM}), 1,5 \mathrm{mM}$ de $\mathrm{MgCl}_{2} 100 \mathrm{ng}$ primer, 0,2 $\mathrm{mM}$ dNTP, uma unidade de Taq DNA Polimerase (Invitrogen), e $20 \mathrm{ng}$ de DNA. Foram utilizados seis primers de 10 pares de bases. As reações de RAPD foram amplificadas em um termociclador "Eppen- 
dorf Mastercycler® Gradient", programado para 40 ciclos, com um passo inicial de desnaturação a $94^{\circ} \mathrm{C}$ por quatro minutos e um passo final de extensão a $72^{\circ} \mathrm{C}$ por cinco minutos. Cada ciclo consistiu de um minuto a $94^{\circ} \mathrm{C}$, um minuto a $40^{\circ} \mathrm{C}$ e dois minutos a $72^{\circ} \mathrm{C}$.

\section{Análise dos dados}

As bandas em cada loco foram identificadas manualmente por comparação com o padrão 100pb Ladder (100 a 2072 pb). Baseando-se na presença ou ausência de bandas de tamanhos moleculares idênticos (mesmo loco), foram usados para a construção de uma matriz de similaridade com base no cálculo do coeficiente de similaridade de Jaccard (Sneath; Sokal, 1973), codificando a presença da banda no gel 1 e a sua ausência como 0 .

\section{Agrupamento}

A fim de representar graficamente 0 padrão de divergência genética, a matriz de similaridade foi submetida a uma análise de agrupamento UPGMA (Unweighted Pair-Group Method Using na Arithmetic Average).

As análises de divergência genética (Coeficiente de Jaccard e UPGMA) foram realizadas utilizando o pacote NTSYS 1.5 (Numerical Taxonomy and Multivariate Analysis System) (ROHLF, 1989).
A variabilidade genética entre as linhagens foi determinada pelo índice de Shannon e pela porcentagem de locos polimórficos, calculados pelo programa Popgen 1.31 (YEH et al., 1999).

Os valores de divergência genética entre as linhagens, as correlações entre as matrizes e as permutações foram calculadas pelo teste de Mantel, pelo método Monte Carlo (1000 permutações), utilizando o coeficiente de Jaccard, pelo programa Mantel-Struct (MILER, 1999).

\section{Resultados e discussão}

\section{Extração de DNA}

O DNA se apresentou com bandas íntegras e sem rastro, indicando que não ocorreu degradação e nem contaminação com excesso de proteína. A razão absorbância a 260/280nm apresentou-se entre 1,8 a 2,2, conforme o recomendado por Ferreira; Grattapaglia (1998) e Barbosa Neto (1998).

\section{Amplificação}

Foram avaliados seis primers de dez bases previamente selecionados. Foram selecionados somente os locos em que as bandas se apresentavam nítidas. Na Tabela 1 pode-se observar a seqüência dos primers, loci total e tamanho dos fragmentos amplificados.

\section{TABELA 1 - Seqüência dos primers, loco total e tamanho dos fragmentos amplificados nas linha- gens de tilápia do Nilo (Oreochromis niloticus).}

Table 1 - Primers sequence, total loco and amplified fragment sizes, in the Nile tilapia's strand (Oreochromis niloticus).

\begin{tabular}{|l|l|l|}
\hline Primers & Seqüência $\left(\mathbf{5}^{\prime} \rightarrow \mathbf{3}^{\prime} \mathbf{)}\right.$ & $\mathbf{N} \mathbf{o}^{\mathbf{}}$ de locos total \\
\hline C05 & CAG GCC TTC C & 8 \\
C08 & AAT CGG GCT G & 7 \\
D07 & TTC CGA ACC C & 4 \\
D01 & GGG TAA CGC C & 4 \\
D02 & GTG ATC GCA G & 4 \\
C07 & AGT CAG CCA C & $\mathbf{3 4}$ \\
\hline Total
\end{tabular}


Foram obtidos com os seis primers 34 loci, sendo que o primer C05 foi o que apresentou mais locos (8), todos os primers apresentaram amplificações para todas as linhagens. Povh et al. (2003) realizaram uma análise genética entre as linhagens de tilápia do Nilo (O. niloticus), Chitralada e Supreme, e encontram amplificação apenas na linhagem Supreme (11 loci), com três primers testados.

O maior loco $(2000 \mathrm{pb})$ e o menor (300 pb) foram obtidos pela amplificação com o primer D01. O marcador 100 pb DNA Ladder, representado no gel pelas bandas de 2072 a 100 pares de bases, foi eficiente para determinar o tamanho aproximado dos locos.

Barman et al. (2003), para estimar a variação genética entre quatro espécies de carpas indianas, utilizaram 34 primers e obtiveram produtos amplificados entre 25 a 1500 pb.

Liu et al. (1999), na análise da variação genética entre catfishs, obtiveram também produtos com boas amplificações na faixa de 200 a 1500 pb. Estes dados apresentam-se muito próximos aos encontrados neste estudo.

No gênero Steindachnerina, Oliveira et al. (2002) observaram 98 locos quando analisaram a diversidade genética utilizando sete primers com o tamanho do produto amplificado variando entre 330 e $2400 \mathrm{pb}$.

Liu et al. (1999) citaram que RAPD possui boa reprodutividade quando se usa primers de qualidade.
As linhagens apresentaram porcentagem de locos polimórfico de 64,71\% para a linhagem Chitralada Codapar, 47,06\% para linhagem Supreme, 73,53\% para linhagem Boaukè e 79,41\% para Chitralada Aquabel. Portanto, existe uma menor variabilidade genética na linhagem Supreme em relação às demais linhagens. Esta pode ser explicada pelo tempo de introdução da linhagem que ocorreu em 2002, quando comparada com as outras linhagens (Bouaké foi introduzida em 1971 e Chitralada em 1996), entretanto, o polimorfismo depende da forma como as populações foram construídas.

Os valores encontrados da variabilidade genética não foram semelhantes aos encontrados por Povh (2004), onde foram estimados 18,9\% e $36,7 \%$ para a linhagem Bouaké e Chitralada, respectivamente.

Segundo Mather (2001), o nível de caracterização genética em populações de tilápia representa importantes recursos para o melhoramento do cultivo desta espécie. A identificação das linhagens pode orientar o cruzamento, que pode ser usado para explorar o efeito da heterose.

\section{Dissimilaridade e variabilidade genética.}

Os valores de dissimilaridade genética nas linhagens de tilápia do Nilo, Chitralada Aquabel, Supreme, Bouaké e Chitralada Codapar, são apresentados na Tabela 2.

\section{TABELA 2 - Valores de divergência genética nas linhagens de tilápia do Nilo (Oreochromis niloticus), Chitralada Aquabel, Supreme, Bouaké e Chitralada Codapar, obtidos pelo coeficiente de Jaccard, utilizando o programa Mantel-Struct.}

Table 2 - Genetic divergence values in the Nile Tilapia's strand (Oreochromis niloticus), Aquabel Chitralada, Supreme, Bouaké and Codapar Chitralada, using Jaocard coefficient, through MantelStruct program.

\begin{tabular}{|l|l|l|l|l|}
\hline & Chitralada A & Supreme & Bouaké & Chitralada C \\
\hline Chitralada A & 0,765599 & - & - & - \\
Supreme & 0,850559 & 0,766948 & - & - \\
Bouaké & 0,846983 & 0,818057 & 0,779689 & - \\
Chitralada C & 0,803376 & 0,892855 & 0,797376 & 0,610530 \\
\hline
\end{tabular}


O valor de divergência genética mostrouse maior para a linhagem Bouaké, mas muito próximo para as demais linhagens.

Os valores de divergência encontrados apresentaram-se muito superiores aos encontrados por Povh (2004), Moreira et al. (2003), Asltolphi (2003) e Freitas; Galetti Jr. (2003). Este fato pode ser devido ao baixo número de primers usados e poucos loci encontrados.

\section{TABELA 3 - Índice de Shannon nas linhagens de tilápia do Nilo (oreochromis niloticus) Chitralada Aquabel, Supreme, Bouaké e Chitralada Codapar, obtidos pelo programa Popgen. Table 3 - Shannon indicator of Nile Tilapia's strand (Oreochromis niloticus), Aquabel Chitralada, Supreme, Bouake and Codapar Chitralada, using Popgen program.}

\begin{tabular}{|l|l|}
\hline Linhagens & Índice de Shannon \\
\hline Chitralada Aquabel & 0,3090 \\
Supreme & 0,1767 \\
Bouaké & 0,3272 \\
Chitralada Codapar & 0,4240 \\
\hline Geral & $\mathbf{0 , 3 9 8 0}$ \\
\hline
\end{tabular}

O menorvalor do índice de Shannon para a linhagem Supreme indica uma menor variabilidade genética em relação às demais linhagens, assim como a porcentagem de loci polimórficos foi menor nesta espécie, sua menor variabilidade genética pode ser explicada pela forma que esta foi construída, por meio de seleção de reprodutores, se estes tinham baixa variabilidade genética, esta será mantida ao longo do tempo, se não houver entrada de novos genótipos nesta população.

Os valores do índice de Shannon não foram semelhantes aos encontrados por Povh (2004), trabalhando com dois lotes de reprodutores das linhagens Bouaké e Chitralada encontrou 0,104 e 0,068 e 0,198 e 0,214, respectivamente. Entretanto, valores superiores $(0,500,0,540$ e 0,580$)$ foram obtidos por Prioli et al. (2002) em três populações do gênero Astyanax.

Prim et al. (2001) avaliaram a variabilidade genética da rã-touro gigante, Rana catesbeiana, proveniente de populações dos Estados de Goiás, Pará e Paraná e concluíram que a variação genética intrapopulacional de $65,15 \%$ foi maior que a variação entre populações, que foi de 34,85 . Angel (2002), estudando a diversidade genética de três populações de Halodule wrightii, usando RAPD, encontrou aproximadamente $60,0 \%$ de variação genética entre as populações.

A variabilidade genética é de extrema importância para o progresso no melhoramento genético. Segundo Rye; Refstie (2000), a alta fecundidade da maioria das espécies aquáticas é evidência da larga variação de genética aditiva, o que pode proporcionar o sucesso de implementação de programas de seleção. Segundo Astolphi (2003), um requisito inicial para aplicação da seleção é a existência da variabilidade, portanto, 0 conhecimento da variabilidade genética de populações sujeita à seleção é o primeiro passo em um programa de melhoramento, visando ao desenvolvimento de uma linhagem.

Pelo dendrograma (Figura 1), não houve separação das linhagens em populações distintas. Este resultado difere do encontrado por Povh (2004), onde houve a formação de grupo da linhagem Bouaké e outro grupo para a linhagem Chitralada, mas resultados semelhantes foram encontrados por Benites (2003), que não encontrou a formação de grupos para as linhagens Bouaké, Chitralada e Híbrido intra-específico. 
FIGURA 1 - Dendrograma obtido pelo agrupamento UPGMA de tilápia do Nilo (Oreochromis niloticus) das linhagens Chitralada Aquabel (L1), Supreme (L2), Bouaké (L3) e Chitralada Codapar (L4), pelo coeficiente de Jaccard, utilizando o programa NTSYS.

Figure 1 - Tree structure using the UPGMA grouping of Nile Tilapia's strand (Oreochromis niloticus) of Chitralada Aquabel (L1), Supreme (L2), Bouake (L3) and Chitralada Codapar (L4) strand, using Jaocard coefficient, through NISYS program.

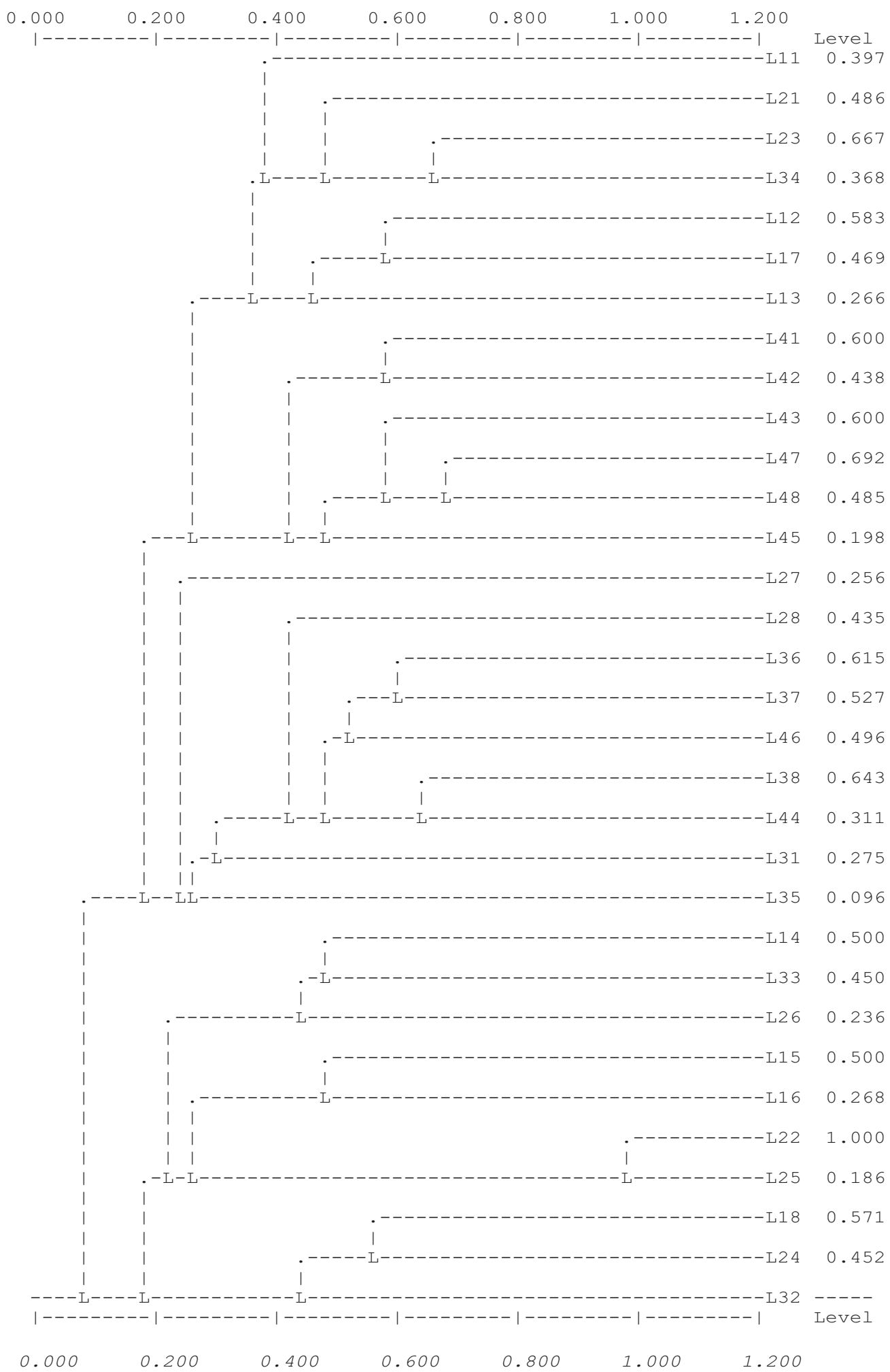


Posteriormente, pesquisas com maior número de primers e outras metodologias serão essenciais para estimar a distância genética entre as linhagens de tilápias cultivadas, objeto deste experimento, com a proposta de gerar bons híbridos e implementarprogramas de monitoramento e melhoramento genético de reprodutores desta espécie.

\section{Conclusões}

As análises com RAPD deste trabalho não permitiram a caracterização genética de quatro populações de Tilápias do Nilo, provavelmente devido ao pequeno número primers usados.

Pelos resultados obtidos no primeiro experimento, para estas condições de cultivo, podese inferir que a linhagem Supreme apresentou um desempenho geral superior com relação às demais linhagens avaliadas, comprovando o efeito do melhoramento genético sobre as características produtivas.

\section{Referências}

ASTOLPHI, J. L L. Avaliação da diversidade genética entre a geração parental e sua progênie selecionada de tilápia do Nilo (Oreochromis niloticus) da linhagem Chitralada com uso do marcador de RAPD. 2003. 24 f. Dissertação (Mestrado em Produção Animal-Zootecnia) - Universidade Estadual de Maringá, Maringá, 2003.

BARBOSA NETO, J. F. Seleção assistida por marcadores moleculares. In:__. MILACH, S. C. K. Marcadores moleculares em plantas. Porto Alegre: Sandra Milach, 1998. p. 75-88.

BARDAKCI, F. E.; SKIBINSKI, D. O. F. Application of the RAPD technique in tilapia fish: species and subspecies identification. Heredit., Oxford, v. 73, p. 117-123, 1994.

BARMAN, H. K. et al. Genetic variation between four species of Indian major carps as revealed by random amplified polymorphic DNA assay. Aquaculture, Amsterdam, v. 217, p. 115-123, 2003.

BENITES, C. Análise por RAPD, da diversidade genética entre diferentes linhagens de Tilápia do Nilo (Oreochromis niloticus). 2002. 23 f., Dissertação (Mestrado em Produção Animal-
Zootecnia) - Universidade Estadual de Maringá, Maringá, 2002.

DINESH, K. R.; LIM, T. M.; CHAN, W. K.; PHANG, V. P. E. Genetic variation inferred from RAPD fingerprinting in three species of tilapia. Aquaculture International, Amsterdam, v. 4, p. 19-30, 1996.

FEDERIZ I, L. C. Estrutura de um programa de melhoramento de plantas e possíveis aplicações de marcadores moleculares: visão do melhorista. In: FEDERIZ I, L. C; MILACH, S. C. K. Marcadores moleculares em plantas. Porto Alegre: Sandra Milach, 1998. p. 3-15.

FERREIRA, M. E.; GRATTAPAGLIA, D. Introdução ao uso de marcadores moleculares. 3. ed. Brasília, DF: EMBRAPA, 1996.

FUNGARO, M. H. P.; VIEIRA, M. L C. Marcadores moleculares. In: FUNGARO, M. H. P.; VIEIRA, M. L. C SERAFINI, L A.; BARROS, N. M.; DE AZEVEDO, J. L. Biotecnologia na agricultura e na agroindústria. Guaíba: Agropecuária, 2001. p. 153-199.

JHINGRAN, V. G.; GOPALAKRISHNAN, V. Catalogue of cultivated aquatic organisms. FAO Fisheries Technical Paper, n. 130, 1974.

JONES, C. J. et al. Reproducibility testing of RAPD, AFLP and SSR markers in plants by a network of European laboratories. Molecular Breeding, v. 3, p. 381-390, 1997.

KOH, T. L; KHOO, G.; FAN, K. Q.; PHANG, V. P. E. Genetic diversity among wild forms and cultivated varieties of Discus (Symphyso don spp.) as revealed by Random Amplified Polymorphic DNA (RAPD) fingerprinting. Aquaculture, Amsterdam, v. 173, p. 485-497, 1999.

LU, Z. J.; ARGUE, P. L. DUNHAM, R. A. Random Amplified Polymorphic DNA markers: usefulness for gene mapping and analysis of genetic variation of catfish. Aquaculture, Amsterdam, v. 174, p. 5859, 1999.

MILACH, S. C. K. Biotecnologia ciência \& desenvolvimento: marcadores de DNA. Porto Alegre: UFRGS, 2002.

MILEER, M. MANTEL-ESTRUCT: a program for the detection of population structure via mantel tests. Journal Heded, Cary, v. 90, p. 258-259, 1999. 
MULLIS, K.; FALOONA, F. Specific synthesis of DNA in vitro via a polymerase catalysed chain reaction. Methods Enzymol, Oxford, v. 55, p. 335350, 1987.

OLIVEIRA, A. V. etal. Diversity and genetic distance in populations of Steindachnerina in the Upper Paraná river floodplain. Genética, v. 115, n. 3, p. 259-257, 2002.

PILIAY, T. V. R. Aquaculture: principles and practices. Oxford: Blackweel, 1990.

POPMA, T. J.; LOVSHIN, L L Tilápia especial. Panorama da Aqüicultura, Rio de Janeiro, v. 5, n. 27, p. 7-13, 1995.

POVH, J. A. Estimativa da diversidade gnética em linhagens de Tilápia do Nilo (Oreochromis niloticus). 2004. 13 f. Dissertação (Mestrado em Produção Animal- Zootecnia)-Universidade Estadual de Maringá, Maringá, 2004.

POVH, J. A. Análise de RAPD (random amplified polymorphic dna) em duas linahgens de Tilápia do Nilo (Oreochromis niloticus). In: CONGRESSO BRASILEIRO DE ZOOTECNIA, 13., 2003, Santa Maria. Anais... Santa Maria: ABCZ, 2003. p. 298.
PRIM, E. C. P.; PÁDUA, J. T.; BATAUS, L A. M. Variabilidade genética e produtiva da rã-touro gigante, Rana catesbeiana, proveniente de populações dos estados de Goiás, Pará e Paraná, criadas em sistema intensivo de cultivo. In: CONGRESSO BRASILEIRO DE ZOOTECNIA, 11., 2001, Goiânia; CONGRESSO INTERNAIONALDEZOOTECNIA, 3., 2001, Goiânia. Anais... Goiania: UEG, 2001. p. 293.

ROHLF, F.J. NTSYS-Pc: Numerical Taxonomy and Multivariate Analysis System. New York: Exeter, 1989.

SNEATH, P. H. A, SOKAI, R. R. Numerical toxonomy. San Francisco: Freeman, 1973.

THYS, D. F. E. An annotated bibliography of Tilapia (Pisces, Cichlidae). Mus. R. Afr. Cent. Doc. Zool., v. 14, 1969.

WILUAMS, J. G. K. et al. DNA polymorphisms amplified by arbitrary primers are useful as genetic markers. Nucleic Acids Research., Amsterdam, v. 18, n. 22, p. 6531-6535, 1990.

YEH, F. C.; BOYLE, T. Y. Z.; XIYAN, J. M. POPGENE Version 131: Microsoft Window-based freeware for population genetic analysis. University of Alberta and Center for International Forestry Research, 1999. 